\title{
Calcium butyrate: Anti-inflammatory effect on experimental colitis in rats and antitumor properties
}

\author{
GIUSEPPE CELASCO ${ }^{1}$, LUIGI MORO ${ }^{2}$, CATERINA AIELLO $^{3}$, KATIA MANGANO $^{3}$, \\ ANGELA MILASI $^{3}$, CINZIA QUATTROCCHI $^{3}$ and ROBERTO DI MARCO ${ }^{3,4}$ \\ ${ }^{1}$ Cosmo R\&D S.p.A., Lainate; ${ }^{2}$ Cosmo S.p.A., Lainate; ${ }^{3}$ Cosmo R\&D S.p.A., Catania Laboratory, Catania; \\ ${ }^{4}$ Department of Medicine and Health Sciences, University of Molise, Campobasso, Italy
}

Received January 15, 2014; Accepted March 25, 2014

DOI: $10.3892 / b r .2014 .273$

\begin{abstract}
Butyric acid is a physiological component of the colonic environment that possesses anti-inflammatory and antitumor properties, among others. However, little is known regarding its effects following direct application on the colonic surface. This study was conducted to investigate the topical anti-inflammatory effect of calcium butyrate in chemically-induced colitis in rats and to evaluate its antitumor properties in vivo and in vitro. The anti-inflammatory activity of calcium butyrate was evaluated in dinitrobenzene sulfonic acid-induced colitis in rats, following intracolonic instillation for 6 consecutive days and its in vivo antitumor activity was evaluated in F344 rats with the azoxymethane (AOM)-induced aberrant crypt foci (AFC) test, following intracolonic instillation for 4 weeks. The in vitro antiproliferative activity was assessed by incubation for $48 \mathrm{~h}$ with the HT29, SW620 and HCT116 intestinal tumour cell lines to evaluate the rate of ${ }^{3} \mathrm{H}$-thymidine uptake. In dinitrobenzene-induced colitis, the intracolonic instillation of calcium butyrate completely prevented body weight reduction in the animals and counteracted the local noxious effects of the irritant by reducing colon edema $(-22.7 \%, \mathrm{P}=0.048)$ and the area of mucosal damage $(-48 \%, \mathrm{P}=0.045)$. In the AOM-induced AFC test, the intracolonic instillation of calcium butyrate significantly reduced the number of AFC in the entire colon $(-22.7 \%, \mathrm{P}<0.05)$. Calcium butyrate, following incubation with the HT29, SW620 and HCT116 tumour cell lines, induced a significant antiproliferative, dose-dependent effect $(\mathrm{P}=0.046$ to $\mathrm{P}=0.002)$ in all three strains, as measured by the reduction in ${ }^{3} \mathrm{H}$-thymidine uptake. Calcium butyrate directly applied to the mucosa of the rat colon was able to ameliorate colonic inflammation, suggesting a possible beneficial role in the treatment of inflammatory colon diseases. Moreover, calcium butyrate exhibited notable
\end{abstract}

Correspondence to: Professor Roberto Di Marco, Department of Medicine and Health Sciences, University of Molise, Via Francesco de Sanctis 1, Campobasso I-86100, Italy

E-mail: roberto.dimarco@unimol.it

Key words: calcium butyrate, short-chain fatty acids, inflammatory bowel disease, colorectal cancer, experimental colitis antitumor effects in vivo and in vitro; however, their clinical relevance requires confirmation by additional clinical investigations.

\section{Introduction}

Butyric acid is a short-chain fatty acid produced in the colon by microflora fermenting dietary fibres, starch and lactate $(1,2)$. The rationale supporting the use of butyric acid in intestinal disorders is associated with its well recognized ability to supply energy to the colocytes in order to regulate their metabolism, control their motility and water/ electrolyte absorption and protect against infections and the onset of inflammatory processes $(1,3,4)$. Moreover, butyric acid is actively involved in the control of the pathological growth of the colocytes (5-8), directing their replication through mechanisms involving inhibition of DNA synthesis and restoration of apoptosis (6,9-17). These mechanisms are closely associated with the properties of butyric acid acting as a potent histone deacetylase inhibitor and as a p21 and p53 gene activator (18-25). The preventive effects of butyric acid on colorectal cancer may also be mediated by enhancing TGF- $\beta$ signalling and its suppressor function in the gut epithelial cells (26). Butyric acid is also a potent activator of acid sphingomyelinase (27), leading to the production of well known antiproliferative molecules, such as ceramide and sphingosine (28-30). The multiple effects of butyric acid on the biology of colocytes prompted the investigation of the anti-inflammatory properties of calcium butyrate directly applied on the colon surface in a chemically induced model of experimental colitis, in order to evaluate its possible role in colon cancer development in vivo and in vitro.

\section{Materials and methods}

Ethical and general considerations. All the in vivo experiments were approved by the local Institutional Ethics Committee and were performed in agreement with the Italian Legislative Decree 116/27.01.1992 regarding the protection of animals used for experimental or other scientific purposes. All the experiments used animals kept in temperature- and light-controlled rooms, maintained at a constant temperature of $\sim 24^{\circ} \mathrm{C}$ and a 12 -h light/dark cycle. The animals were fed 
standard animal pellets (Mucedola s.r.l., Milan, Italy) and tap water ad libitum.

Effect of calcium butyrate on dinitrobenzene (DNB)-induced colitis in rats. Groups of 8-10 male Wistar rats (Charles River, Lecco, Italy) for a total of 27 animals weighing $\sim 200-250 \mathrm{~g}$ were used. The test was performed as previously described (31), with the exception of a longer treatment duration. Colitis was induced in animals fasted overnight and under light ether anaesthesia, by instillation into the colonic lumen of $30 \mathrm{mg}$ DNB dissolved in $0.25 \mathrm{ml}$ ethanol $50 \%$. The administration of the irritant was performed through a rectal catheter (outer diameter $0.3 \mathrm{~mm}$ ) placed $\sim 7 \mathrm{~cm}$ proximally to the anus. Following DNB instillation and insufflation with $0.5 \mathrm{ml}$ air, the catheter was removed. Calcium butyrate (CAS 5743-36-2; Garuda Chemicals, Mumbai, India) was suspended in SV17874, composed of $0.4 \%$ Tween-80, $0.5 \%$ carboxymethylcellulose and $0.9 \%$ benzyl alcohol in sterile saline, and was administered into the colon by the same procedure as described for the irritant, at concentrations of 10 and $30 \mathrm{mg}$ in $0.25 \mathrm{ml}$. The administration lasted for 6 days, including 3 days prior to and 3 days after colitis induction. Twenty-four hours after the last administration, the animals were weighed and sacrificed by $\mathrm{CO}_{2}$ inhalation. Immediately after the sacrifice the intestine was exteriorized. The colon was isolated, cleaned from the mesenterium, vessels and fat and was placed unstretchted on a ruler. Starting from the anal verge, a $10-\mathrm{cm}$ segment of the distal colon was cut and was weighed after rinsing the lumen with saline. Subsequently, the isolated portion of the colon was longitudinally opened and pinned down on a cork table with the mucosal surface facing the observer. The mucosal damage area (MDA) was measured with the Image-Pro Plus image analysis system, version 3.0 for Windows 95/NT (Media Cybernetics 1993-97, www.mediacy.com). The image acquisition was performed with a PC camera (Chicony iCam 330; Chicony Electronics Co., Ltd., New Taipei, Taiwan) and the MDA was expressed in $\mathrm{mm}^{2}$.

Effect of calcium butyrate on induction of aberrant crypts (ACs) and aberrant crypt foci (ACF) in rat colon. Groups of 10-12 female F344 rats (Charles River), for a total of 33 animals, weighing $\sim 150 \mathrm{~g}$, were used. The animals received two subcutaneous injections of $15 \mathrm{mg} / \mathrm{kg}$ body weight azoxymethane (AOM; Sigma-Aldrich, Milan, Italy), with an interval of 7 days between the injections, to induce the formation of ACs in the colon. Calcium butyrate was suspended in SV17874 and administered once a day, at concentrations of 0.7 and $3.5 \mathrm{mg}$ in $0.25 \mathrm{ml}$, for 4 consecutive weeks, beginning on the day prior to the first AOM injection. The administration of calcium butyrate was performed through a rectal catheter (outer diameter $0.3 \mathrm{~mm}$ ) placed $\sim 7 \mathrm{~cm}$ proximally to the anus. Twenty-four hours after the last intracolonic administration, the animals were euthanized by $\mathrm{CO}_{2}$ inhalation. Immediately after the sacrifice, the entire colon was isolated, cleaned from the mesenterium, vessels and fat and was longitudinally opened. The opened colon was transversally cut at the splenic flexure level to separate the proximal from the distal colon. The segments were rinsed with buffer saline and were fixed flat in $10 \%$ phosphate-buffered formalin $(\mathrm{pH}$ 6.9-7.1) for $16 \mathrm{~h}$. The segments were stained with methylene blue $(0.01 \%$ in phosphate-buffered neutral formalin) for $30 \mathrm{~min}$, briefly washed with deionised water and placed on microscope slides with the mucosal side facing up. The mucosal surface was then investigated under a microscope (magnification, x40) for the detection of ACs and ACF. The ACs were distinguished from the surrounding normal crypts by their easier staining, increased size, thicker epithelial lining and increased pericryptal zones (32). The number of single ACs and the number of foci containing ACs were counted and recorded separately for the proximal and distal colon.

Effect of calcium butyrate on proliferation of colon cancer cells. HT29, SW620 and HCT116 human colon cancer cells were obtained from the National Research Institute on Cancer (Genova, Italy). All the cell lines were grown in complete Dulbecco's modified Eagle's medium (DMEM; Invitrogen Life Technologies, Milan, Italy), supplemented with $1 \%$ L-glutamine $200 \mathrm{mM}, 1 \%$ penicillin-streptomycin $10,000 \mathrm{U} / \mathrm{ml}$ and $10 \%$ foetal bovine serum (FBS; Invitrogen Life Technologies) and were maintained at $37^{\circ} \mathrm{C}$ in an humidified incubator with $50 \mathrm{ml} / 1 \mathrm{CO}_{2}$. The cells were then dispensed in 96-well Nunclon Surface plates (Thermo Scientific, Milan, Italy) at a density of $3 \times 10^{5}$ cells $/ \mathrm{ml}$ and were incubated for $48 \mathrm{~h}$ at $37^{\circ} \mathrm{C}$ with calcium butyrate. Calcium butyrate was suspended in DMEM without FBS and was tested at concentrations of 1.25 , 2.5 and $5 \mathrm{mM}$. Complete DMEM was used as negative control. During the last $18 \mathrm{~h}$ of incubation the cells were labelled with methyl ${ }^{3} \mathrm{H}$-thymidine (Amersham Biosciences, Little Chalfont, Buckinghamshire, UK). The effect of calcium butyrate on the proliferation of HT29, SW620 and HCT116 cells was assessed by the ${ }^{3} \mathrm{H}$-thymidine uptake test, which was performed at the end of the incubation period. The radioactivity was read with a Beckman LS6000SC Beta Counter (Beckman Coulter Inc., Fullerton, CA, USA) and the proliferation activity was expressed as mean counts per minute.

Statistical analysis. Significant differences among the experimental groups were evaluated with one-way analysis of variance, in which pairwise multiple comparisons were performed with the Student's t-test. $\mathrm{P}<0.05$ was considered to indicate a statistically significant difference.

\section{Results}

In DNB-induced colitis in rats (Table I), the intracolonic instillation of $30 \mathrm{mg}$ calcium butyrate completely prevented body weight reduction in the animals $(\mathrm{P}=0.002)$ and counteracted the local noxious effects of the irritant, reducing colon edema ( $-23 \%$, $\mathrm{P}=0.048)$ and the area of mucosal damage $(-48 \%, \mathrm{P}=0.045)$.

In the AOM-induced ACF test, the occurrence of ACs and ACF in the distal colon of the control group was $~ 2.5$ times higher compared to that in the proximal colon (Table II), resembling the different incidence of colorectal cancer detected in humans. The intracolonic instillation of $3.5 \mathrm{mg}$ calcium butyrate reduced the global occurrence of ACs and ACF in both colonic districts, with a more evident activity in the distal colon. The inhibitory effect reached a statistical significance for both AC and ACF in the distal colon (-24.7 and $-23.5 \%$, respectively; $\mathrm{P}<0.05)$ and for $\mathrm{ACF}$ in the proximal colon $(-20.2 \%, \mathrm{P}<0.05)$. 

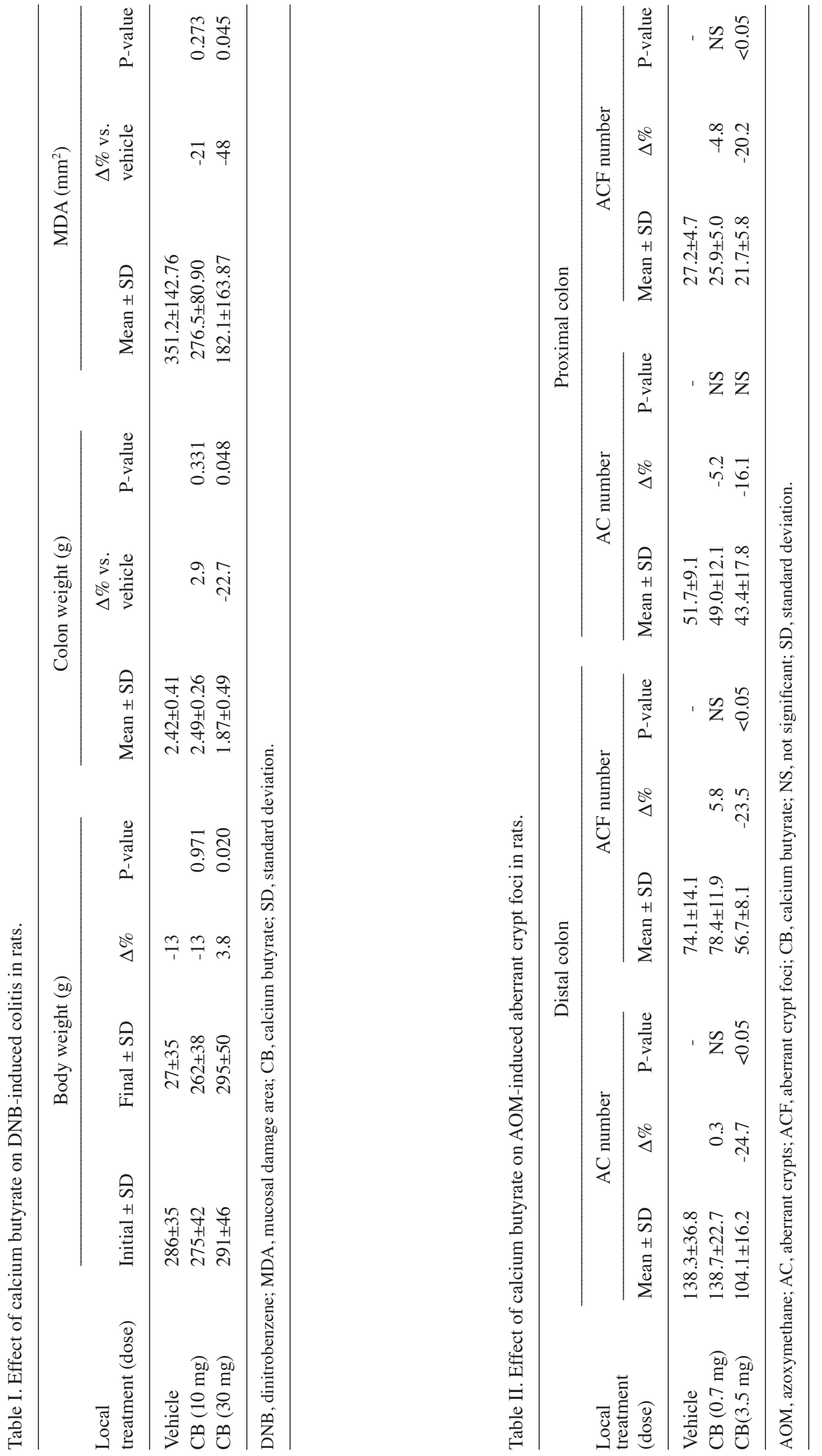
The results of ${ }^{3} \mathrm{H}$-thymidine uptake after a 48 -h incubation of HT29, SW620 and HCT116 cells with calcium butyrate are presented in Table III. A significant, dose-dependent inhibitory effect on cell proliferation was observed in all three cell clones at any tested dose $(\mathrm{P}=0.046$ to $\mathrm{P}=0.002)$. These cells differed regarding sensitivity to calcium butyrate and, as a general rule, SW620 and HCT116 cells appear to be more sensitive compared to HT29 cells.

\section{Discussion}

The anti-inflammatory activity of butyric acid has been already described in the literature $(1,3,8)$; however, to the best of our knowledge, there is no currently available report regarding the effects of local administration to the colon. Our experiments demonstrated that calcium butyrate exerted a notable anti-inflammatory effect when directly instilled on the mucosal surface of the colon in rats, suggesting that oral formulations engineered to deliver butyric acid to the colon may be useful in the treatment of inflammatory bowel diseases. Our results reinforce previous, although sparse, clinical observations suggesting an efficacy of oral and rectal preparations of butyric acid in the management of inflammatory (33-36) and non-inflammatory (37) bowel disorders. In our experiments, we also demonstrated that calcium butyrate exhibited a notable antitumor activity in vivo, inducing a significant reduction in the occurrence of ACs and ACF in the colon of rats challenged with AOM. These findings may be of value, since ACF are considered to be dysplastic lesions, potentially evolving to colon cancer $(32,38)$. Despite the fact that previous in vivo studies did not provide conclusive results regarding the beneficial effect of oral butyrate on the prevention of precancerous lesions in the gut $(39,40)$, our results demonstrated that these effects were achieved when calcium butyrate was delivered directly into the colon. The apparent higher susceptibility of the distal colon to calcium butyrate represents further evidence of the local activity of this substance. The discrepancy between our results and those of previous studies lies with the fact that, in our study, calcium butyrate was administered topically, whereas following oral administration of plain formulations, the rapid and complete absorption of butyric acid in the upper part of the gastrointestinal tract may have prevented its adequate availability to the colon. This suggests that, for calcium butyrate to be active by the oral route, it should be administered in formulations delivering the substance directly to the colon, in order to provide and maintain effective concentrations in the mucosa to confer anticarcinogenic benefits. Finally, we demonstrated that calcium butyrate inhibited the proliferation of human HT29, SW620 and HCT116 colon cancer cell lines in vitro. The inhibitory effect of calcium butyrate on cancer cell proliferation was dose-dependent and did not appear to be attributable to a direct cytotoxic mechanism, since butyric acid, when incubated with normal cells, such as human lymphocytes, did not affect their viability (41). The complex of in vivo and in vitro antitumor activities of calcium butyrate opens new perspectives in the long-term strategies of colorectal cancer prevention in humans, considering that butyric acid is a substance physiologically produced in the colon, cost-effective and very well tolerated. When compared to other pharmacological approaches 
recently suggested for the prevention of colon cancer (i.e., COX-2 inhibitors and other NSAIDs), calcium butyrate offers the additional advantage of lack of interference with complex biological systems, such as prostaglandins, leukotrienes and thromboxanes, whose long-term disruption may be associated with unwanted and unpredictable effects. The data obtained from our experiments suggest a possible beneficial role of topical calcium butyrate administration in the treatment of inflammatory colon diseases. Moreover, calcium butyrate exhibited notable antitumor activity in vivo and in vitro; however, their clinical relevance requires confirmation by further well-designed clinical investigations.

\section{References}

1. Velazquez OC, Lederer HM and Rombeau JL: Butyrate and the colonocyte. In: Dietary Fiber in Health and Disease. Plenum Press, N.Y, pp123-134, 1977.

2. Bourriaud C, Robins RJ, Martin L, Kozlowski F, Tenailleau E, Cherbut $\mathrm{C}$ and Michel C: Lactate is mainly fermented to butyrate by human intestinal microflora but inter-individual variation is evident. J Appl Microbiol 99: 201-212, 2005.

3. Mortensen PB and Clausen MR: Short-chain fatty acids in the human colon: relation to gastrointestinal health and disease. Scand J Gastroenterol Suppl 216: 132-148, 1996.

4. Sengupta S, Tang CL, Wong CS, Tjandra JJ and Gibson PR: Colonic epithelial atrophy induced by a fibre-free diet in rats is reversed by minimal amounts of luminal butyrate, but only in the short term. ANZ J Surg 72: 871-876, 2002.

5. Orchel A, Molin I, Dzierzewicz Z, Latocha M, Weglarz L and Wilczok T: Quantification of p21 gene expression in Caco-2 cells treated with sodium butyrate using real-time reverse transcriptionPCR (RT-PCR) assay. Acta Pol Pharm 60: 103-105, 2003.

6. Ruemmele FM, Scwatrz S, Seidman EG, Dionne S, Levy E and Lentze MJ: Butyrate induced Caco-2 cell apoptosis is mediated via the mitochondrial pathway. Gut 52: 94-100, 2003.

7. Rouet-Benzineb P, Aparicio T, Guilmeau S, Pouzet C, Descatoire V, Buyse M and Bado A: Leptin counteracts sodium butyrate-induced apoptosis in human colon cancer HT-29 cells via NF-kappaB signaling. J Biol Chem 279: 16495-16502, 2004.

8. Augenlicht LH, Mariadason JM, Wilson A, Arango D, Yang WC, Heerdt BG and Velcich A: Short chain fatty acids and colon cancer. J Nutr 132: 3804S-3808S, 2002.

9. Wachtershauser A and J Stein: Rationale for the luminal provision of butyrate in intestinal diseases. Eur J Nutr 39: 164-171, 2000.

10. Caderni G, Luceri C, Lancioni L, Tessitore L and Dolara P Slow-release pellets of sodium butyrate increase apoptosis in the colon of rats treated with azoxymethane, without affecting aberrant crypt foci and colonic proliferation. Nutrition and Cancer 30: 175-181, 1998.

11. Hernandez A, Thomas R, Smith F, Sandberg J, Kimschung DH and Evers BM: Butyrate sensitizes human colon cancer cells to TRAIL-mediated apoptosis. Surgery 130: 265-272, 2001.

12. Kim YH, Park JW, Lee JY and Kwon TK: Sodium butyrate sensitizes TRAIL-mediated apoptosis by induction of transcription from DR5 gene promoter through Sp1 sites in colon cancer cells. Carcinogenesis 25: 1813-1820, 2004.

13. Avivi-Green C, Polak-Charcon S, Madar Z and Schwartz B Different molecular events account for butyrate-induced apoptosis in two human colon cancer cell lines. J Nutr 132: 1812-1818, 2002.

14. Menzel T, Schauber J, Kretch F, Kudlich T, Mclcher R, Gostner A, Scheppach W and Luhrs H: Butyrate and aspirin in combination have an enhanced effect on apoptosis in human colorectal cancer cells. Eur J Cancer Prev 11: 271-281, 2002.

15. Avivi-Green C, Polak-Charcon S, Madar Z and Schwartz B Apoptosis cascade proteins are regulated in vivo by high intracolonic butyrate concentration: correlation with colon cancer inhibition. Oncol Res 12: 83-95, 2000.

16. Haza AI, Glinghammar B, Grandien A and Rafter J: Effect of colonic luminal components on induction of apoptosis in human colonic cell lines. Nutr Cancer 36: 79-89, 2000.

17. Litvak DA, Hwang KO, Evers BM and Townsend CM Jr: Induction of apoptosis in human gastric cancer by sodium butyrate. Anticancer Res 20: 779-784, 2000.
18. Berni Canani R, Di Costanzo M and Leone L: The epigenetic effects of butyrate: potential therapeutic implications for clinical practice. Clinical Epigenetics 4: 1-7, 2012.

19. Kobayashi H, Tan EM and Fleming SE: Sodium butyrate inhibits cell growth and stimulates p21WAF1/CIP1 protein in human colonic adenocarcinoma cells independently of p53 status. Nutr Cancer 46: 202-211, 2003.

20. Orchel A, Molin I, Dzierzewicz Z, Latocha M, Weglarz L and Wilczok T: Quantification of p21 gene expression in Caco-2 cells treated with sodium butyrate using real-time reverse transcriptionPCR (RT-PCR) assay. Acta Pol Pharm 60: 103-105, 2003.

21. Chen YX, Fang JY, Zhu HY, Lu R, Cheng ZH and Qui DK: Histone acetylation regulates p21 WAF1 expression in human colon cancer cell lines. World J Gastroenterol 10: 2643-2646, 2004.

22. Johnstone RW: Histone-deacetylase inhibitors: novel drugs for the treatment of cancer. Nat Rev Drug Discov 1: 287-299, 2002.

23. Monneret C: Histone deacetylase inhibitors. Eur J Med Chem 40: $1-13,2005$.

24. Joseph J, Wajapeyee N and Somasundaram K: Role of p53 status in chemosensitivity determination of cancer cells against histone deacetylase inhibitor sodium butyrate. Int J Cancer 115: 11-18, 2005.

25. Davie JR: Inhibition of histone deacetylase activity by butyrate. J Nutr 133 (7 Suppl): 2485S-2493S, 2003

26. Nguyen KA, Cao Y, Chen JR, Townsend CM and Ko TC: Dietary fiber enhances a tumor suppressor signalling pathway in the gut. Ann Surg 243: 619-627, 2006.

27. Wu J, Cheng Y, Jönsson BA, Nilsson A and Duan RD: Acid sphingomyelinase expression is stimulated by butyrate but not functionally involved in cell proliferation and apoptosis in HT29 and HepG2 cells. J Lipid Res 46: 1944-1952, 2005.

28. Ahn EH and Schroeder JJ: Sphingoids bases and ceramide induce apoptosis in HT-29 and HCT-116 human colon cancer cells. Exp Biol Med (Maywood) 227: 345-353, 2002.

29. Parodi PW: Conjugated linoleic acid and other anticarcinogenic agents of bovine milk fat. J Dairy Sci 82: 1339-1349, 1999.

30. Berra B, Colombo I, Sottocornola E and Giacosa A: Dietary sphingolipids in colorectal cancer prevention. Eur J Cancer Prev 11: 193-197, 2002.

31. Celasco G, Moro L, Bozzella R, Mangano K, Quattrocchi C, Aiello C, Donia M, Fagone P and Di Marco R: Efficacy of intracolonic administration of low-molecular-weight heparin CB-01-05, compared to other low-molecular-weight heparins and unfractionated heparin, in experimentally induced colitis in rat Dig Dis Sci 53: 3170-3175, 2008.

32. Wargovich MJ, Harris C, Chen CD, Palmer C, Steel VE and Kelloff GJ: Growth kinetics and chemoprevention of aberrant crypts in the rat colon. J Cell Biochem Suppl 16G: 51-54, 1992.

33. Vernia $P$, Annese V, Bresci G, d'Albasio G, d'Incà R, Giaccari S, Ingrosso M, Mansi C, Riegler G, Valpiani D and Caprilli R: Topical butyrate improves efficacy of 5-ASA in refractory distal ulcerative colitis: results of a multicentre trial. Eur J Clin Invest 33: 244-248, 2003

34. Vernia P: Butyrate in the treatment of ulcerative colitis. Dig Liv Dis Suppl 1: 27-30, 2007.

35. Assisi RF; GISDIStudy Group: Combined butyric acid/mesalazine treatment in ulcerative colitis with mild-moderate activity. Results of a multicentre pilot study. Minerva Gastroenterol Dietol 54: 231-238, 2008

36. Di Sabatino A, Morera R, Ciccocioppo R, Cazzola P, Gotti S, Tinozzi FP, Tinozzi S and Corazza GR: Oral butyrate for mildly to moderately active Crohn's disease. Aliment Pharmacol Ther 22: 789-794, 2005.

37. Scarpellini E, Lauritano EC, Lupascu A, Petruzzellis C, Novi ML, Roccarina D, Gabrielli M, Serricchio M, Gasbarrini G and Gasbarrini A: Efficacy of butyrate in the treatment of diarrhoea-predominant irritable bowel syndrome. Dig Liv Dis Suppl 1:19-22, 2007

38. Pereira MA, Barnes LH, Rassman VL, Kelloff GV, Steele VE: Use of azoxymethane-induced foci of aberrant crypts in rat colon to identify potential cancer chemopreventive agents. Carcinogenesis 15: 1049-1054, 1994.

39. Velazquez OC, Lederer HM and Rombeau JL: Butyrate and the colonocyte. Implications for neoplasia. Dig Dis Sci 41: 727-739, 1996.

40. Sengupta S, Muir GJ and PGibson PR: Does butyrate protect from colorectal cancer? J Gastroenterol Hepatol 21: 209-218, 2006.

41. Sigh NP and Lai HC: Synergistic cytotoxicity of artemisin and sodium butyrate on human cancer cells. Anticancer Res 25: 4325-4331, 2005. 